\title{
Methodology of the research of organizational and economic bases of development of agro, ethno and spiritual tourism in the Republic of Kazakhstan
}

\author{
Abdizhapar Saparbayev ${ }^{1}$, Gulnara Saparova ${ }^{2 *}$, Aiymzhan Makulova ${ }^{3}$, Aliya Imatayeva ${ }^{3}$, \\ Aisha Abdulkhalil ${ }^{2}$ \\ ${ }^{1}$ Academy Kainar, Almaty, Kazakhstan \\ ${ }^{2}$ Al-Farabi KazNU, pr. al Farabi, 71, 050040 Almaty, Republic of Kazakhstan \\ ${ }^{3}$ University Narxoz, Almaty, Kazakhstan
}

\begin{abstract}
The article discusses the problems and prospects for the development of ethno, eco, agro and spiritual tourism. An important problem of ethno-tourism is the problem of increasing the excursion attractiveness of countries and regions. The main environmental problem of the development of society is the protection and storage of natural identity and security. This work is the result of research conducted by the author for the period 20122017 using statistical and financial reporting of Kazakhstan tourism. The work includes methods for comparing current years and past (base).Purpose of scientific work is analysis of the trends of development and approaches to the development of the state programs of the development of agro-, Etna and spiritual tourism in the economy Of the Republic Kazakhstan. Lies in the fact that in further development of methodological base the estimation of the effectiveness of agro-, Etna and spiritual tourism on the basis of innovation approach and unity of the processes of their functioning. The methods proposed in this work show what methods of programs can be used for the development of tourism both within the state and abroad.
\end{abstract}

\section{Introduction}

The modern tourism industry is one of the largest, most profitable and most dynamically developing sectors of the world economy. According to the UNWTO (World Tourism Organization), tourism is in fourth place in world exports of goods and services $(7.4 \%)$, second only to exports of cars, chemical enzymes and fuels. Tourism, as a service sector, is a significant tool for redistributing national income within the country and has a multiplier effect on the development of many sectors of the economy. Trends in world socio-economic development show that currently more than half of gross domestic product is produced in the world of services. Kazakhstan, having a rich tourist and recreational potential, is characterized by an insufficient level of tourism development. The share of tourism in gross domestic product (calculated as food services and accommodation) is about $0.3 \%$. Tourism

${ }^{1}$ Corresponding author: gulnara_sto@mail.ru 
in Kazakhstan relies mainly on the local population, including business and professional trips of foreign residents. Agro, ethno and spiritual tourism in the modern world more and more confidently occupies its vast niche in the entertainment and tourism industry [1].

The key to the successful development of tourism services is government support. The government in the field of the long-term development program of Kazakhstan, taking into account the constant and rapid increase in tourism services, its powerful impact on the environment, all sectors of the economy and the welfare of society, has identified the tourism industry as a priority that actively affects the economy of entire regions of the country. The creation and management of functioning entities in the field of tourism is closely related to the development of the construction of infrastructure, transport, trade, cultural, public utilities, and medical services. Tourism has been singled out as one of the seven priority clusters of the economy, which needs priority development and expansion. The consequence of the stable growth of tourism services is, first of all, a general increase in the standard of living of the population, improvement of social infrastructure, and an increase in the trend towards economic and cultural development. The value of tourism services in the world is constantly growing, due to the strengthening of its influence on the national economy of many countries [2].

The task of agrotourism is to increase the level of development of individual settlements, increase the level of migration flow from city to city by creating additional jobs, and reduce the level of social tension as a result of the organization of new specific sectors of the local economy. According to official statistics, almost half of the population of Kazakhstan lives in rural areas, and the poverty level in rural areas exceeds the urban level by more than 3 times. Many academics believe that by studying case studies, we can critically evaluate our problems in tourism and the possibility of eliminating them [3].

\section{Methodology}

\subsection{Identification of social and economic factors that influence regional tourism development}

The modern dynamic development of the tourism and entertainment industry, which acts as the largest sector of the world economy, urgently requires diversification, that is, the active expansion of the services offered.

Only activities aimed at creating new segments of the market, meeting the increasing consumer demand as fully as possible, can increase the rate of competitiveness at the required level. The dynamics of the industry development shows, over the last thirty years, an increase in the number of tourists by four times. Tourism revenues increased twenty-five times. According to the forecast of the World Tourism Organization (Tourism: 2020 Vision), the average annual growth rate of world tourism will be $4 \%$ by 2020 , and the number of international tourist trips will increase to 1.6 billion. An important factor in the development of agro, ethno and spiritual development of tourism can be a certain event that will attract tourists, that is, the event can revitalize the city, park, resort and various places, making them more attractive and visited again. Also in event tourism, the main advantage is that for our country it can be used for the greatest benefit to combat seasonal demand [4]. Tourism (the French tourisme, from tour walk, a trip), a travel (a trip, a campaign) in free time, one of types of active holiday. The deep connection of nomad culture with nature and life - makes it necessary to choose the methodology of research in close connection with the state, ethnic associations, social organizations, masters, guardians of folk traditions and so on. Also an important aspect in the integrated approach are tourism companies and professional guides, which have wide opportunities in advertising and promotion of tourism in Kazakhstan. It is 
ecology, as the main factor affecting the satisfaction of tourists on a trip, which can be quantified along with economic and social factors [5].

One of the important criteria is also considered rural economy - it is a system of socioeconomic relations in rural areas, Aimed at the integrated and rational use of resource potential, the development and effective functioning of social and engineering infrastructure, Preservation of the unique way of life of the population in rural areas, it is necessary to create in rural areas the most complete set of various economic forms and types of activities for all basic components of rural society. Economic diversification can solve the problem of the rational use of resources and their effective allocation among alternative uses.

Of course, the development of the agricultural industry should be the basis for any rural settlement, regardless of the organizational form in which it will be implemented. But in modern conditions, agricultural development measures should be aimed not only at developing agricultural production, but also at local industry, tourism, social infrastructure and other activities that contribute to improving the efficiency of the rural economy and improving rural living conditions. Rural tourism is a non-agricultural activity in rural areas. Rural tourism is a profitable sector of the economy of any country, as is already believed in many European countries. This direction allows to involve the rural population living in rural areas and at the same time preserve the local color, customs, and way and culture [6].

\subsection{Identify important documents, directions, programs, strengths and weaknesses through SWOT analysis affecting tourism development}

Main documents it:

1. Concept of development of tourism industry of the Republic of Kazakhstan till 2020 (from May 19, 2014 № 508)

2. Concept of development of tourism industry of the Republic of Kazakhstan till 2023 (dated June 30, 2017 № 406)

Selected 3 directions: agro-, ethno-and spiritual tourism should become a business card of the tourist product of Kazakhstan and become the foundation for creating the image of a unique and unique product, which distinguishes Kazakhstan from the rest of the republics of the Central Asian region.

The foundation of the tourist product should be the creation of gate-auls, where master classes will be held on the invention of traditional productions, such as: cats, tuskysis, etc., souvenir products, pottery and blacksmith crafts, musical instruments.

As part of the development of the Digital Kazakhstan program, the Digital Portal project is being developed - an electronic system that gives access to information where an ordinary tourist, has the opportunity to order tickets, book hotels and have feedback. It will also be offered an atlas with directions of the list and places of attractions [7].

In determining the resource region, it is necessary to identify weaknesses and strengths and thus determine the direction of development, i.e. we make SWOT analysis.

Table 1. SWOT analysis in region.

\begin{tabular}{|l|l|}
\hline \multicolumn{1}{|c|}{ Weak strengths } & \multicolumn{1}{c|}{ Weak } \\
\hline Developed chain of hotels of different levels & Lack of convenient routes (road quality) \\
\hline Development of food point infrastructure & Poor service quality, no service \\
\hline Development of food point infrastructure & Shortageofqualifiedpersonnel \\
\hline \multicolumn{1}{|c|}{ Opportunities } & Seasonalityofvisits \\
\hline Development of new tourist destinations and routes & Tnsufficientfinancing \\
\hline Attractinginvestors & Decrease in solvency of the population \\
\hline Supportofthestate & \\
\hline
\end{tabular}


Based on the data obtained, it is possible to draw a conclusion on the potential of the region, to identify growth points, as well as to formulate new approaches in policy documents to minimize the impact of negative factors. For the proper selection of specific tasks in hotel management, the practice of foreign countries for sustainable development serves as a motivation:

- Need to adopt "green" practices $\S$ Accept all the innovations and brands of the operator, owner or guest, which entail development stability.

- And the most important thing is a good customer relationship [8].

Table 2.Volume of rendered services, places of accommodation (thousand tenge) [9].

\begin{tabular}{|l|c|c|c|c|}
\hline \multicolumn{1}{|c|}{ Indicators } & 2015 year & 2016 year & 2017 year & 2018 year \\
\hline $\begin{array}{l}\text { Provision of services by } \\
\text { hotels }\end{array}$ & 66210021,1 & 74342033,5 & 96615886,7 & 89706419,2 \\
\hline $\begin{array}{l}\text { Provision of weekend and } \\
\text { other short-term } \\
\text { accommodation }\end{array}$ & 5920307,8 & 8151421,1 & 11231776,6 & 13569071,2 \\
\hline $\begin{array}{l}\text { Camping, recreational car } \\
\text { park and trailer park } \\
\text { accommodation services }\end{array}$ & 13237,2 & 26074,9 & 37928,7 & 62116,5 \\
\hline $\begin{array}{l}\text { Services in other types of } \\
\text { housing }\end{array}$ & 453662,2 & 333 905,1 & 474168,4 & 610650,0 \\
\hline \multicolumn{1}{|c|}{ Total } & $\mathbf{7 2 5 9 7 ~ 2 2 8 , 3}$ & $\mathbf{8 2 ~ 8 5 3 ~ 4 3 4 , 6}$ & $\mathbf{1 0 8 3 5 9 7 6 0 , 4}$ & $\mathbf{1 0 3 ~ 9 4 8 ~ 2 5 6 , 9}$ \\
\hline
\end{tabular}

This table gives the concept of profitability of one of the infrastructure elements in terms of accommodation of tourists and entering, in terms of types of accommodation. We see from the data in the table that every year the volume of hotel services, weekend accommodation, camping and other type's increases, proving that the methods used work steadily and that we can use them in practice. It is necessary to conduct continuous analysis in order to gain new professional knowledge about specific factors affecting eco-, agro-tourism [10].

Profit growth in 2018 compared to 2015 is 23,496,398.1 thousand tenge for hotel services, which can be called a good indicator, but 2018 compared to 2017 decreased by $6,909,469.5$ thousand tenge, trained by the fact that many did not use hotel services. Within the framework of our study, allocate ethno and agro resources.

These two main groups are complemented by data on activities that form the basis of tourism development. The development of the region through festivals and quests of ethnographic, cultural, archaeological, etc., makes the region attractive for tourists. This allows the evolution of the types of tourism developing in the territory of specific regions.
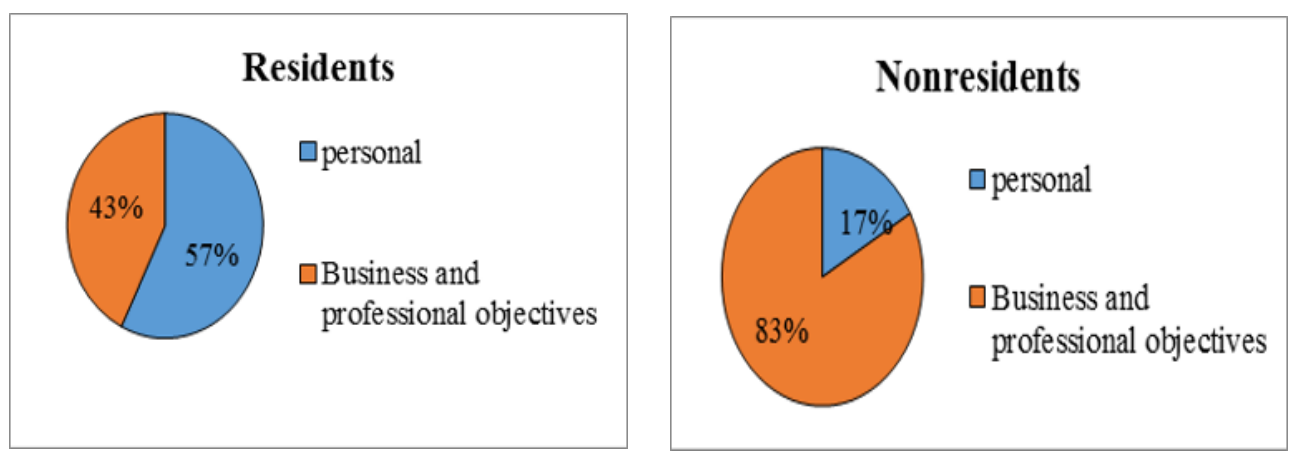

Fig. 1.Served visitors with accommodation on travel targets in 2018[9]. 


\subsection{Methods for assessing environmental and resource potential and development of a methodology for integrated assessment of the resource potential of tourism at the regional level}

The methodology for assessing the environmental and resource potential and developing a methodology for a comprehensive assessment of the resource potential of tourism at the regional level is presented in Table 1.

Table 3.Methods for assessing environmental and resource potential.

\begin{tabular}{|c|l|}
\hline Name of a method & \multicolumn{1}{c|}{ Characteristic } \\
\hline Expensive & $\begin{array}{l}\text { Represents the valuation of natural resources, characterized by the } \\
\text { current cost of extraction, development or use of natural resource } \\
\text { potential components }\end{array}$ \\
\hline Productive & $\begin{array}{l}\text { Shows that valuation is inherent only in elements of nature whose } \\
\text { exploitation generates income }\end{array}$ \\
\hline Expensive and resource & $\begin{array}{l}\text { Determines the cost of natural resources, taking into account the costs } \\
\text { of their development and the income from their use }\end{array}$ \\
\hline Rent & $\begin{array}{l}\text { Means the valuation of natural resources whose stock is limited, that } \\
\text { is, the rent (price) for their use }\end{array}$ \\
\hline $\begin{array}{c}\text { Alternative cost method } \\
\text { for natural resources }\end{array}$ & $\begin{array}{l}\text { Helps to estimate a natural resource whose price is undervalued or } \\
\text { non-existent by accounting for lost income that could be generated } \\
\text { using the natural resources in question for another purpose }\end{array}$ \\
\hline Reproduction & $\begin{array}{l}\text { Assumes the price of a natural resource to be defined as a set of costs } \\
\text { needed to regenerate a degraded natural resource }\end{array}$ \\
\hline $\begin{array}{c}\text { Method of environmental } \\
\text { assessment }\end{array}$ & $\begin{array}{l}\text { This is a determination of the level of environmental protection of } \\
\text { natural resource potential }\end{array}$ \\
\hline Animated method & Calculation and forecasting of income from increased tourist spending \\
\hline
\end{tabular}

In this regard, it can be noted that the assessment of the ecological and resource potential of the region should include the specificity of the specialization of the region: both with an agricultural or industrial focus and with the type of tourism activity.

Figure 2 shows the stages of development of a methodology for integrated assessment of the resource potential of tourism at the regional level. This methodological approach focuses on the assessment of tourism resources, which is complemented by the assessment of socioeconomic factors affecting tourism development. Evaluation analysis involves consistent identification of private indicators of individual assessment objects, calibration of assessment of individual components of tourism resource potential, and as a result - general integrated assessment of tourism resource potential [11].

The functions of ecological tourism were defined as:

- providing spiritual and culturological knowledge to tourists;

- emotional improvement, disposal of a "city" stress;

- visit of places being property of world culture and archeology;

- knowledge acquisition about cultures and ethnoses, to their way of life and traditions of this region;

- attraction of investments into infrastructure;

- motivation to creation of environmentally friendly and safe forms of environmental management;

- providing local population with jobs, attraction of profit to the region;

- opening of again training centers and courses of retraining of experts to the tourist and nature protection sphere;

- protection and safety of unique territories of the region;

- to propagandize ecotourism and rational environmental management; 
- creation of an information system of data on sights and unique places of regions.

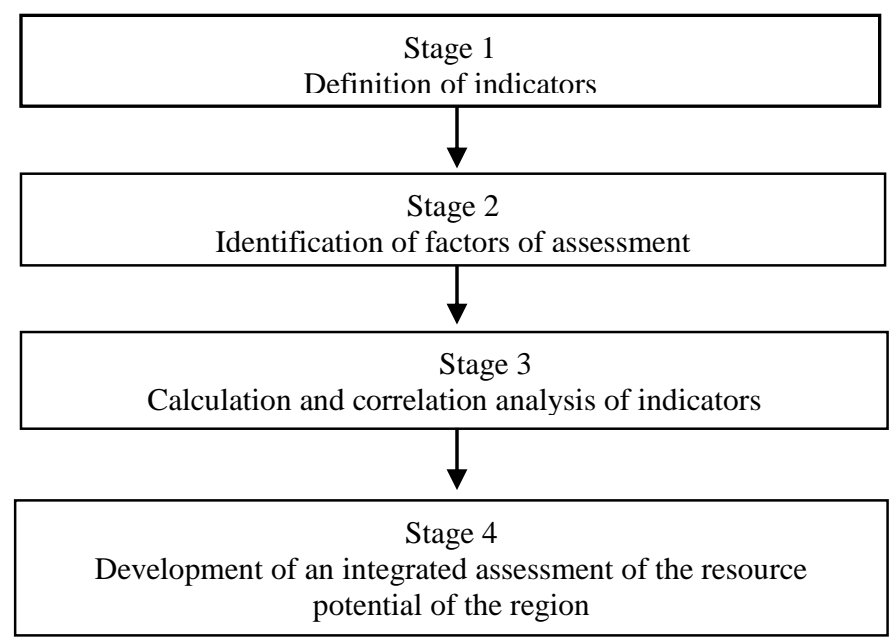

Fig. 2. Development of a methodology for integrated assessment of the resource potential of tourism at the regional level [9]

The sequence data given above allow to identify factors affecting the development of the tourism segment in Kazakhstan:

I. External:

a) Geographical:

- economical and geographical and transit opportunities;

- cultural and historical links

b) Political:

existence of interstate agreements and participation in the international organizations and unions

c) Economic:

- population density

- standard of living

- economic indicators of the country.

d) Information:

- knowledge and creation of uniform base of types of tourism in RK;

- information illumination in Internet sources;

- existence of maps and atlases of tourist routes.

II. Internal:

e) Local:

- level of service;

- crime rate

f) Legal:

- regulatory framework of regulation by the tourist of activity;

g) Material

- qualification of experts;

- existence of infrastructure.

As we can see, the possibility of ecotourism is relevant, this implies the possibility of tourism in the fresh air, which increases the usefulness of the stay of tourists, which will lead to greater profit for the country [12]. 
Based on the analysis of methodological approaches to the identification, assessment and analysis of tourism resources, tourism potential in the region shows that the resource potential of tourism is not generally assessed. It can also be said that the most detailed characteristic and informative data are defined only in generalized methods:

$>$ Calculation of private valuation indicators and calculation of integral valuation indicator;

$>$ A combination of qualitative and quantitative assessments of the object being evaluated;

$>$ Comparisons with identical indicators of other regions.

On the basis of all the above, it seems appropriate to use the development of methodologies for assessing the resource potential of tourism at the regional level. Great attention must be paid to the active participation of organizations in the implementation of the environmental system, to provide their staff with environmental education for professional work in eco-tourism [13].

This methodology is useful for state influence on tourism and local self-government bodies, as well as for information support of development and definition of management solutions in the field of tourism development and creation of a single base of tourist facilities.

Mathematical calculation of correlation on the identification of the connection of places of accommodation, thanks to the large influx of visitors (tourists). Therefore, we will carry out a mathematical calculation of the correlation to identify the relationship of placements, thanks to the large influx of visitors (tourists) [14].

For the sustainable development of eco-, agro-tourism, and one should pay attention to the experiences of other countries like the USA, Barcelona, and European countries as a whole. For the quality work of organizations for both the reporting and previous periods, since thanks to past achievements, we can improve our future $[15,16]$.

\section{Results and Discussion}

\subsection{Mathematical Calculation of Correlation on Detection of Location Connection, Thanks to Large Influx of Visitors (Tourists)}

According to this table, the growth of accommodation places is clearly expressed, thanks to the large influx of visitors (tourists). Changes from January-March to January-June amounted to 5,846 beds, Janavara-June to January-September amounted to 7,137 beds.

The largest influx of tourists cost East Kazakhstan region, amounting to 28,211; 29 259; 31 864; Then in the second place on provision of beds it was necessary in Almaty region to make 21,$875 ; 23203 ; 25929$. The lowest influx of tourists was in the Kyzylorda region at 1,$903 ; 1932 ; 1954[17,18]$.

Among the leaders in providing accommodation places are Akmola, Almaty, Karaganinsky, East Kazakhstan, Astana, and Almaty [9].

Average granting beds $=\frac{\text { sumofbeds }}{\text { quantityofbeds }}$

$$
\begin{aligned}
& \text { For I quarter }=\frac{154123}{17}=9066(2) \\
& \text { For II quarter }=\frac{159969}{17}=9410(3) \\
& \text { For III quarter }=\frac{167106}{17}=9830(4)
\end{aligned}
$$


Table 4. One-time accommodation capacity (beds) [9].

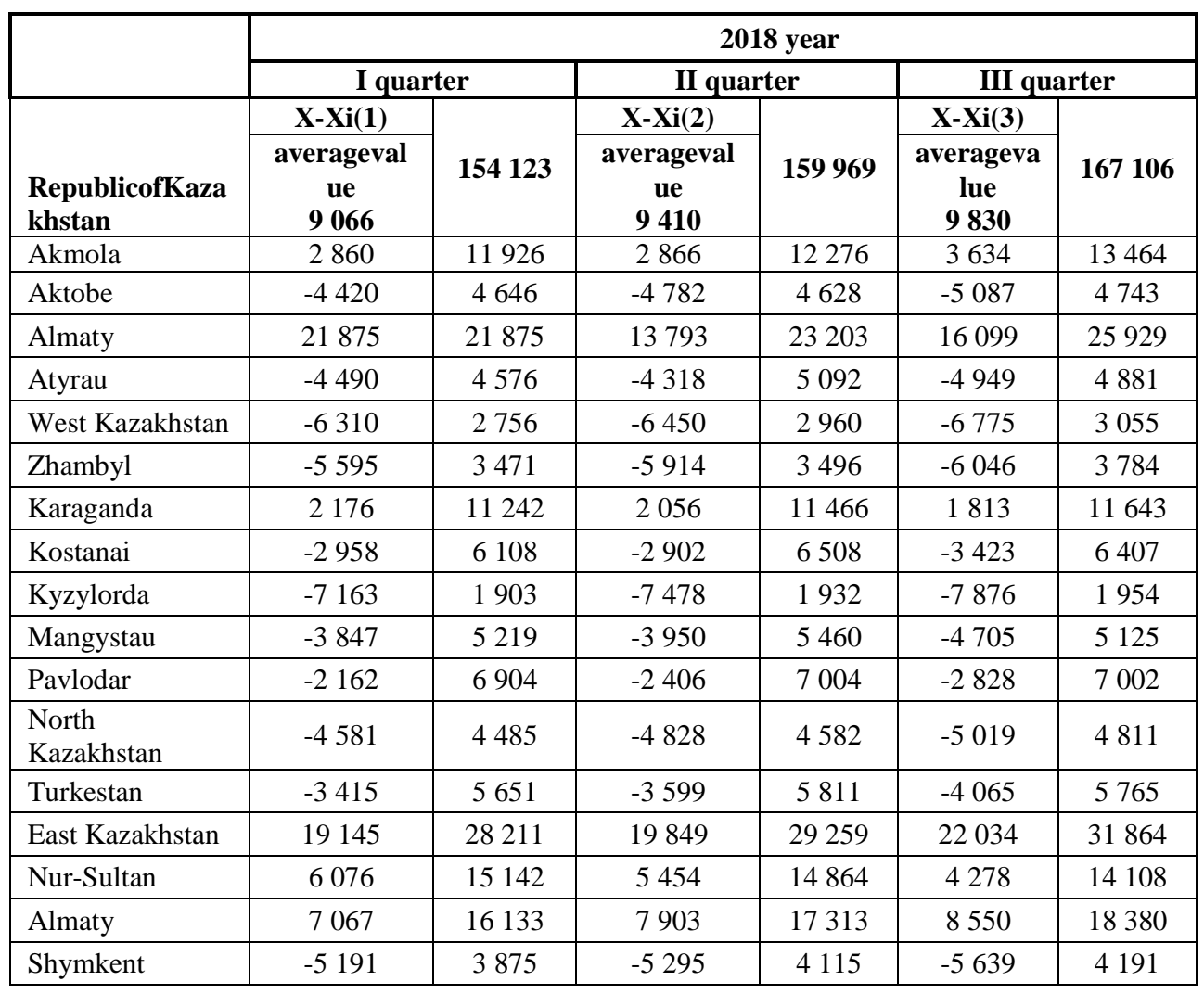

Table 5. Calculation of correlation by Pearson formula [9].

\begin{tabular}{|c|c|c|c|c|c|c|}
\hline $\begin{array}{c}\text { Place- } \\
\text { ments } \\
(\mathbf{X})\end{array}$ & $\begin{array}{c}\text { visitors } \\
(\mathbf{Y})\end{array}$ & $\mathbf{X - X i}$ & $\mathbf{Y - Y i}$ & $\begin{array}{c}(\mathbf{X}-\mathbf{X i}) *(\mathbf{Y}- \\
\mathbf{Y i})\end{array}$ & $\left.\mathbf{( X - X i}^{\wedge}\right)^{\wedge}$ & $(\mathbf{Y - Y i})^{\wedge} \mathbf{2}$ \\
\hline 13464 & 270002 & 3634 & 19,2 & 69920763,05 & 13207666 & 370157229 \\
\hline 4743 & 90415 & -5087 & $-160,3$ & 815650153,3 & 25875175 & 25711330188 \\
\hline 25929 & 721398 & 16099 & 470,6 & 7576871179 & 259185377 & 221497746176 \\
\hline 4881 & 150787 & -4949 & $-99,9$ & 494755371,4 & 24490272 & 9995106481 \\
\hline 3055 & 74090 & -6775 & $-176,6$ & 1196914817 & 45897437 & 31213182649 \\
\hline 3784 & 84917 & -6046 & $-165,8$ & 1002663048 & 36551271 & 27504739626 \\
\hline 11643 & 212572 & 1813 & $-38,1$ & $-69248415,83$ & 3287822 & 1458516537 \\
\hline 6407 & 155571 & -3423 & $-95,1$ & 325818207,2 & 11715318 & 9061427272 \\
\hline 1954 & 42815 & -7876 & $-207,9$ & 1637745813 & 62027670 & 43242174988 \\
\hline 5125 & 191797 & -4705 & $-58,9$ & 277418941,6 & 22134811 & 3476933659 \\
\hline 7002 & 113664 & -2828 & $-137,0$ & 387682382,7 & 7996253 & 18796006767 \\
\hline 4811 & 105016 & -5019 & $-145,7$ & 731467537,8 & 25187999 & 21242050836 \\
\hline 5765 & 117307 & -4065 & $-133,4$ & 542465325,8 & 16522312 & 17810378331 \\
\hline 31864 & 462897 & 22034 & 212,1 & 4674220839 & 485507525 & 45001033612 \\
\hline 14108 & 557127 & 4278 & 306,3 & 1310699291 & 18303297 & 93859188839 \\
\hline 18380 & 786795 & 8550 & 536,0 & 4583203749 & 73106524 & 287330809525 \\
\hline 4191 & 125793 & -5639 & $-124,9$ & 704673771,8 & 31795667 & 15617383281 \\
\hline 167106 & 4262963 & & & $\mathbf{2 6 2 6 2 9 2 2 7 7 4}$ & $\mathbf{1 1 6 2 7 9 2 ~ 3 9 7}$ & $\mathbf{8 7 3} \mathbf{1 8 8} \mathbf{1 6 5 9 9 4}$ \\
\hline 9830 & 250763 & & & & & \\
\hline
\end{tabular}


1. We calculate the sum of the values of $X$ and $Y$ :

$\mathrm{X}=167106$ number of placements (beds)

$\mathrm{Y}=4,262,963$ the number of visitors served at the placements

2. We calculate the arithmetic mean of $X$ and $Y$ :

$X=9830$ number of placements (beds)

$Y=250763$ the number of visitors served at the placements

3. We calculate for each studied value the deviation from the arithmetic mean (X-Xi) and $(\mathrm{Y}-\mathrm{Yi})$, the calculations are shown in table 5

4. The next step is to square each deviation $(\mathrm{X}-\mathrm{Xi} \wedge$ 2$)$ and $\left(\mathrm{Y}-\mathrm{Yi}^{\wedge} 2\right)$

$(\mathrm{X}-\mathrm{Xi})^{\wedge} 2=1162792397$

$(\mathrm{Y}-\mathrm{Yi})^{\wedge} 2=873188165994$

5. We calculate the amount of deviation products

$(\mathrm{X}-\mathrm{Xi}) *(\mathrm{Y}-\mathrm{Yi})=26262922774$

Pearson correlation coefficient formula

$$
\begin{gathered}
r_{B}=\frac{\sum_{i=1}^{n}\left(x_{i}-\vec{x}\right) *\left(y_{i}-\vec{y}\right)}{\sqrt{\sum_{i=1}^{n}\left(x_{i}-\vec{x}\right)^{2} * \sum_{i=1}^{n}\left(y_{i}-\vec{y}\right)^{2}}} \\
r_{B}=\frac{\mathbf{2 6 2 6 2 9 2 2 7 7 4}}{\sqrt{\mathbf{1 1 6 2 ~ 7 9 2 ~ 3 9 7 * 8 7 3 1 8 8 1 6 5 9 9 4}}}=0,824210313
\end{gathered}
$$

This calculation method, the correlation method shows the relationship between the values, in this case we performed a linear calculation of the means, and the final result shows us a strong direct relationship between the values of $\mathrm{X}$ and $\mathrm{Y}$, the data were taken for the III quarter of 2018, and under the value of $X$ - the number of places accommodation (beds), $U$ - the number of visitors served in the accommodation. That is, if our final result is close to 1 , then this value is an indicator of a strong direct relationship, in this example it was 0.82 . We see that for the III quarter the number of lump-sum capacity (beds) for tourist accommodation increases, as our previous values showed that there are more tourists with each quarter, therefore, depending on visitors, the volume of lump-sum capacity increases, and as we see in this regard, the more visitors, the more placements, therefore, in general, all tourism increases.

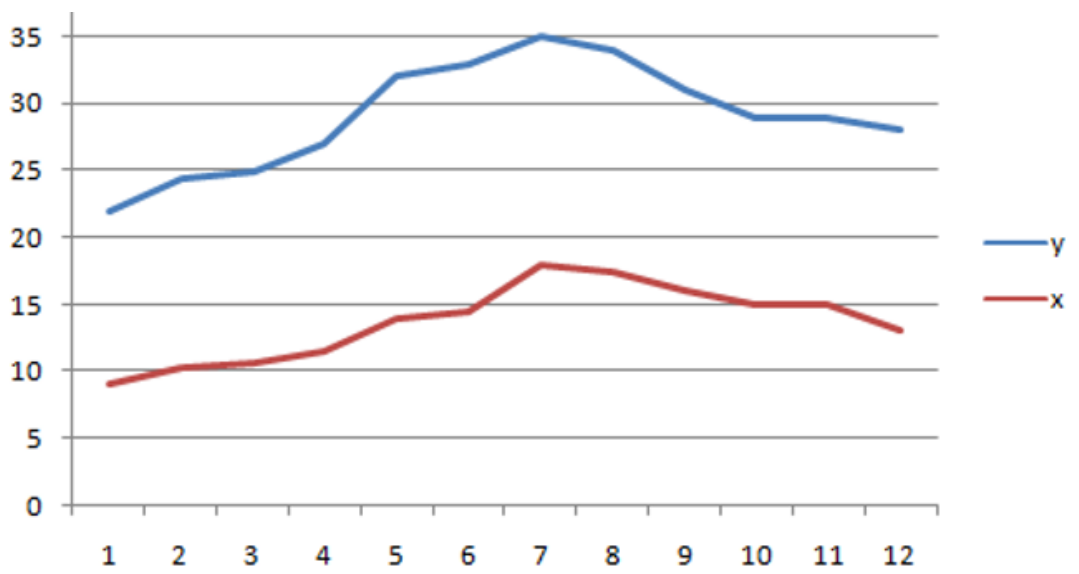

Fig. 3. Strong direct interrelation [9]. 


\section{Conclusion}

The most effective tool for the development of the tourism segment of the economy is State methods for the development of tourism development programmes, concepts and strategies. Therefore, capacity-building, the identification of factors influencing the development or containment of tourism sectors - are becoming significant indicators in development programmes.

State regulation in the field of tourism should take into account regional peculiarities. In order to achieve the goals, it is necessary to adapt to the following factors:

- Increase in political appeal;

- High qualities of tourist services;

- Variety of entertainments, existence of the developed infrastructure, safety;

- Open access;

- Participation of the population, in work various informative channels.

In modern times, it is necessary to involve more the local population and, including young people. As they evolve and evolve to open up productive communities, to new types of population organizations that can help ensure everyone's freedom of personal initiative, meeting important human needs, access to knowledge. This work gives us a basis for the development and approaches to the development of ethno, agro and spiritual tourism in the Republic of Kazakhstan. Using basic methods, based on them, we can improve the quality of the services provided, as well as the overall service of tourism at the regional level. I carried out both theoretical and practical analyses on the development of methods for the improvement and development of tourism. In modern times tourism plays a very huge role in the formation of the state, including the development and evolution of the economy to a new level.

According to the data given in the scientific work, reports and diagrams, we clearly see how the tourism of our state improves every year, and to maintain it at the same level, we must pay more attention to this area. As the attendance of foreigners in Kazakhstan from foreign countries increases every year, therefore we need to increase the places of accommodation, the number of employees, the number of services and their quality. We also see the importance of natural resource potential, which plays an equally important role in the evolution of tourism.

Tourism in the Republic of Kazakhstan is one of the priorities of industrial and innovative development of the national economy. Given that Kazakhstan has a certain economic and unique natural potential, the country has every opportunity to develop different types of tourism: cultural cognitive, ecological, extreme, business, health, etc.

As it was stated in the journal: Journal of Kazakh-Russian International University:

Summing up, let s indicate that analyzing the state of tourism in Kazakhstan at the present stage it is necessary, first of all, to note a certain positive dynamics of its development. Despite the small adjustments made by the world economic crisis, the growth rate of tourism in Kazakhstan continues to show positive dynamics.

Entry and domestic tourism are the most profitable for the developing State, as they lead to an influx of money into the country, thus adding to its budget. Entry and domestic tourism are one of the most highly profitable sectors of the economy in the world, and UNWTO experts predict that growth will continue in the 21 st century despite everything. "

\section{References}

1. Krutikov VK, Yakunina MV, Hudy-Husky D. Improving the tools of state stimulation of the region. Kaluga. Publishing house "IP Yakunina A.V.". 2017 
2. The official page of the Russian translation of the book "Steve Jobs". Electronic resource. [Access Mode]: http: // stevejobsthebio. Com

3. Serra, J., Font, X. \& Ivanova, M. (2017). Creating shared value in the organizations managing the direction: the example of Turisme de Barcelona. Journal of Destination Marketing \& Management, 6 (4), 385-395. DOI: 10.1016 / j.jdmm.2016.06.005

4. Hawkins and Goldblatt, 1995 D. Hawkins, J. Goldblatt The Importance of Event Management for Tourism Education Tourism Vacation Research, 20 (2) (1995), p. 4245

5. Jarvis D., Shtekl N. and Liu H.-B. (2016). The impact of economic, social and environmental factors on travel satisfaction and the likelihood of visitors returning. Tourism Management, 52, 1-18.doi: 10.1016 / j.tourman.2015.06.003

6. Aragon-Correa, J.A., Martin-Tapia, I., de la Torre-Ruiz, J., 2015. issues Sustainability issues and strategies of hospitality and tourism firms. Int. J. Contemp. Hospitality Management. 27 (3), 498-522.

7. On approval of the Concept of development of the tourism industry of the Republic of Kazakhstan until 2023.

8. Melissen, F., van Ginneken, R. \& Wood, R.C. (2016). Sustainability issues and opportunities arising from the separation of owners and operators in hotels. International Journal of Hotel Management, 54, 35-42. DOI: 10.1016 / j.ijhm.2016.01.005 Bendersky Yu. G., Varfolomeev I.V., Lopatin A.P. Problems of economic assessment of the natural resource potential of the Krasnoyarsk Territory. Krasnoyarsk, 2001.S. 8

9. https://stat.gov.kz

10. Lyon A., Hunter-Jones P. \& Warnaby G. (2017). Are we closer to sustainable development? Listening to active stakeholder presentations on tourism development in the Waterberg Biosphere Reserve, South Africa. Tourism Management, 61, 234-247. DOI: 10.1016 / j.tourman.2017.01.01.010

11. Gavrilov A.Yu. Approaches to assessing the resource potential of tourism at the regional level // Materily VIII mezinrodnivedecko -praktickkonferenceнDnyvedy 2012. - Dil 18. Ekonomickevedy: Praha. Publishing House 1. Education and Science s.r.o - 80 stran. 0.25 pp (p. 42-45)

12. Beery, T. \& Jönsson, K.I. (2017). Camping and attachment to places: exploring the possibilities of outdoor recreation in the UNESCO Biosphere Reserve. Journal of Outdoor Recreation and Tourism, 17, 54-63. DOI: 10.1016 / j.jort.2017.01.002

13. Chou, C.-J. (2014). Environmental policy of hotels and personal environmental convictions of employees: interaction and results. Tourism Management, 40, 436-446. DOI: 10.1016/ j.tourman.2013.08.08.001 1

14. Nickerson, N.P., Jorgenson, J. \& Boley, B. B. (2016). Are sustainable tourists a more expensive market? Tourism Management, 54, 170-177. DOI: 10.1016 / j.tourman.2015.11.00.00

15. Wells, V.K., Gregory Smith, D., Taheri, B., Manika, D. and McCowlen, S. (2016). Research on the development of CSR in hereditary tourism. Annals of Tourism Research, 58, 1-17. DOI: 10.1016/ j.annals.2016.01.007

16. Ziyadin, S., Doszhan, R., Saparova, G., Omarova, A. Business tourism as a priority for the development of the tourism industry in the Republic of Kazakhstan, Proceedings of the 32nd IBIMA 2018 - Pages 3379-3383 (2018)

17. Ziyadin, S., Beyzhanova, A., Orazymbetova, A., Yessenzhigitova, R. Agrotourism in the Republic of Kazakhstan: Current status and prospects of development, Proceedings of the 32nd IBIMA 2018 p. 3080-3084 (2018) 
18. Ziyadin, S., \& Takhtaeva, R. Trends and problems in tourism development on the territory of Eastern Kazakhstan region. Actual Problems of Economics,, (9), 232-236. (2014). 